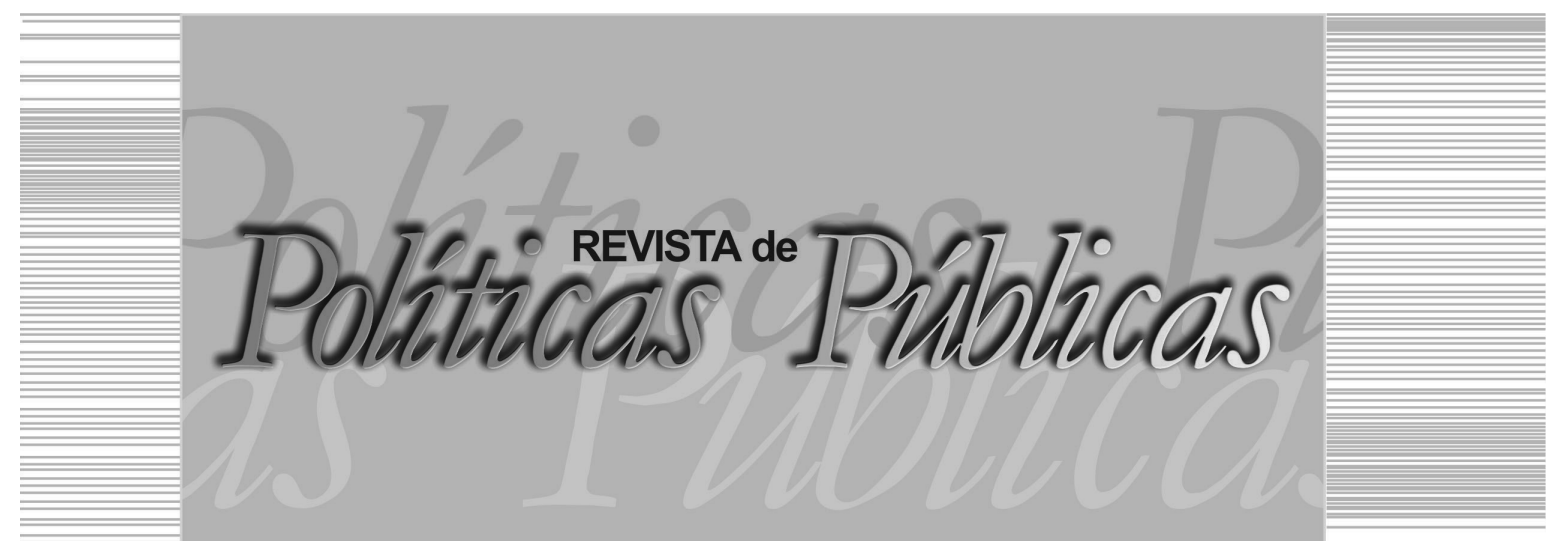

\title{
GESTÃO PÚBLICA E POLITICA DE MOBILIDADE E ARBORIZAÇÃO: conflitos de interesses
}

\author{
Luis Carlos Araújo de Moraes ${ }^{1}$ \\ Agência do Meio Ambiente de Resende (AMAR)
}

\begin{abstract}
Resumo
Atualmente observa-se uma crescente preocupação, por parte da população, de questões ligadas ao ambiente urbano que afetam a qualidade de vida nas nossas cidades. A existência de Políticas Públicas, entre elas, a de Meio Ambiente e de Mobilidade Urbana não garante por si só os anseios da sociedade, pois, muitas das vezes são pensadas, e implantadas, de maneira independente, por conseguinte, atuam de formas concorrentes. A motivação deste estudo partiu da dificuldade de se transitar pelos passeios públicos da cidade de Resende, RJ, tendo em vista os vários obstáculos existentes, assim como a má conservação dos mesmos, bem como a degradação da paisagem urbana, além da carência de pesquisas que relacionem mobilidade, acessibilidade e urbanização urbana. Assim, o objetivo deste artigo é evidenciar os conflitos existentes entre as políticas citadas, sugerindo medidas para compatibilizá-las. A metodologia de pesquisa teve um enfoque qualitativo baseado em um estudo de caso e a investigação utilizada foi o levantamento bibliográfico, análise documental de normas, legislações e procedimentos pertinentes às políticas envolvidas além de registros fotográficos dos conflitos existentes entre elas. O resultado obtido apontou para o comprometimento não só do ambiente natural, quanto da mobilidade e, por conseqüência, a sustentabilidade urbana e a qualidade de vida.
\end{abstract}

\footnotetext{
Turismólogo, Mestre em Turismo e Meio Ambiente pelo Centro Universitário UNA, Funcionário Público da Prefeitura Municipal de Resende e Analista Ambiental da Agência do Meio Ambiente de Resende (AMAR). E-mail: lcambien@hotmail.com / Prefeitura Municipal de Resende: Rua Augusto Xavier de Lima, 251, bairro Jardim Jalisco, Resende - RJ. CEP: 27510-090; Agência do Meio Ambiente de Resende - AMAR: Avenida Rita Ferreira da Rocha, $\mathrm{s} / \mathrm{n}^{\circ}$, Jardim Jalisco, Resende - RJ. CEP: 27.510-060
} 
Palavras-chave: Políticas públicas, arborização urbana, acessibilidade, qualidade de vida.

\title{
PUBLIC MANAGEMENT AND POLITICS OF MOBILITY AND AFFORESTATION: conflicts of interest
}

\begin{abstract}
Currently there is a growing concern on the part of the population of the urban environment issues that affect the quality of life in our cities. The existence of public policies, among them, the Environment and Urban Mobility does not guarantee by itself the desires of society, because they are often designed and implemented, independently, therefore, act of competing forms. The motivation of this study started from the difficulty of transit by public walks of the City of Resende/RJ, in view of the various existing obstacles, as well as poor conservation of same as well as the degradation of the urban landscape, besides the lack of research that relate mobility, accessibility and urban. Therefore, the aim of this article is to highlight the conflicts between these policies and suggest measures to make them compatible. The research methodology was a qualitative approach based on a case study and research was used bibliographic standards, document analysis of laws and procedures relevant policies involved besides photographic records of conflicts between them. The results obtained pointed to the involvement not only of the natural environment, as mobility and by consequence urban sustainability and quality of life.

Key words: Public policies, urban afforestation, accessibility, quality of live.
\end{abstract}

\section{INTRODUÇÃO}

A função que o Estado cumpre em nossa sociedade sofreu inúmeras transformações ao passar do tempo. No século XVIII e XIX, seu principal objetivo era a segurança pública e a defesa externa em caso de ataque inimigo. Entretanto, com a expansão da democracia, as responsabilidades do Estado se diversificaram. Por força Constitucional, no seu art. $182^{\circ}$, o Estado tem o objetivo de ordenar o pleno desenvolvimento das funções sociais da cidade e de garantir o bem-estar de seus habitantes.

Para tanto, o Estado necessita desenvolver uma série de ações e atuar diretamente em diferentes áreas, dentre elas, o meio ambiente e a mobilidade urbana. Para atingir resultados em diversas áreas e promover o bem-estar da sociedade, os governos se utilizam das Políticas Públicas, formuladas por iniciativa do poder executivo ou do legislativo, que podem ser definidas como um conjunto de ações 
e decisões do governo, voltados para solucionar os problemas da sociedade.

Ressalta-se que o Estado brasileiro possui uma organização político-administrativa que compreende a União, os Estados, o Distrito Federal e os Municípios, todos autônomos e, portanto, há uma distribuição das competências administrativas e legislativas entre essas quatro esferas político-administrativas, conforme se verifica em vários dispositivos constitucionais, dentre os quais citam-se os artigos $21^{\circ}, 22^{\circ}, 23^{\circ}, 24^{\circ}, 30^{\circ}$ dentre outros. No art. $23^{\circ}$ encontram-se as competências comuns entre os entes federados, e que, entre elas frisam-se a proteção e garantia das pessoas portadoras de deficiência, proteção das paisagens naturais, do meio ambiente, da fauna $\mathrm{e}$ da flora.

No entanto, para que se alcancem os objetivos da promoção do bem-estar da sociedade, as Políticas Públicas devem estar alinhadas umas com as outras, já que em muitos casos uma tem correlação e afeta as outras, conforme corroborado por Magagnin e Silva (2008), ao citar que o processo de planejamento, em que cada problema urbano deve ser resolvido separadamente, não pode mais ser utilizado para solucionar os atuais problemas urbanos, uma vez que é de conhecimento de pesquisadores que há uma inter-relação entre eles, prova disso está no número excessivo de veículo nas ruas causando congestionamentos que, por sua vez, aumenta a poluição sonora; e a do ar interferindo no clima, tanto em nível global quanto municipal, gerando as ilhas de calor e em ambos os caos afetando a qualidade de vida das pessoas.

De amplo conhecimento são os benefícios paisagísticos, sociais e ambientais, e mais recentemente, na linha da psicologia ambiental e da topofilia de Tuan (1980 e 1983) - que trabalham com a relação afetiva e simbólica da população com as árvores urbanas, oriundos da arborização urbana como, por exemplo, a diminuição das poluições atmosférica e sonora, aumento da retenção de carbono, proteção para avifauna, atua no micro clima regional, além de possuir valor estético, o que leva a um aumento da sensação de bem-estar.

Por outro lado, outra questão - referente à mobilidade urbana, que precisa ser resolvida, é a questão do deslocamento dos pedestres pelas calçadas em precário estado de conservação, desniveladas, com pisos escorregadios e tomadas por obstáculos como postes 
de iluminação, lixeiras, árvores, hidrantes, materiais de construção, cadeiras e mesas de bares, dentre muitos outros, como evidenciado recentemente em divulgação na mídia televisiva. ${ }^{1}$

Ressalta-se que são consideradas pedestres pessoas fisicamente aptas àquelas com dificuldades de locomoção entre elas as que usam cadeiras de roda, muletas, carrinhos de bebê, dentre outras. (AGUIAR, 2010).

Pesquisadores como Carvalho (2006), Lunaro (2006), Keppe Jr. (2007) e Yuassa (2008) avaliam as condições de mobilidade através de estudos sobre a qualidade das calçadas. Outros como Rossetti, Pellegrino e Tavares (2010), Basso e Correa (2014), Martini e outros (2015); dissertaram sobre os benefícios da arborização urbana. Todavia, há uma carência de estudos sobre a correlação e conciliação entre mobilidade, acessibilidade e arborização nos passeios públicos dos centros urbanos.

\section{POLÍTICA PÚBLICA DE MEIO AMBIENTE}

A Política Nacional do Meio Ambiente objetiva a compatibilização do desenvolvimento econômico social com a preservação da qualidade do meio ambiente e do equilíbrio ecológico e tem como um dos princípios a racionalização do uso do solo. (BRASIL, 1981).

A política urbana está positivada no Estatuto da Cidade e mais particularmente nos Planos Diretores de cada município. O objetivo do Estatuto da Cidade é ordenar o pleno desenvolvimento das funções sociais da cidade e da propriedade urbana, mediante diretrizes, entre elas a ordenação e controle do uso do solo de forma a evitar a deterioração das áreas urbanas, da poluição e da degradação ambiental. (BRASIL, 2001).

Já o plano diretor visa harmonizar o processo de apropriação do espaço urbano, conjugando os diferentes interesses e necessidades econômicos, sociais, culturais e ambientais da população. Percebe-se, pois, a compatibilização das Leis.

Dentre os desafios da atualidade que os governos enfrentam estão temas polêmicos como saneamento básico, disposição final de resíduos sólidos e a arborização urbana. Apesar da existência das garantias constitucionais e da legislação infraconstitucional que proíbem o lançamento de esgotos, sem o devido tratamento, em corpos hídricos, exigem o depósito do lixo em aterros sanitários, e que 
restringe o corte de árvores, verifica-se ausência de eficácia dessas garantias pela não aplicação efetiva dessas políticas públicas pelo Poder Público.

Segundo Provenzi (2008), em muitas cidades brasileiras as ações de planejamento não vêm acontecendo de forma adequada, pois muitos projetos se baseiam em métodos empíricos, desprovidos de um conhecimento real do assunto, o que acarreta problemas nas redes de distribuição de energia elétrica, telefônica, calçadas, sistemas de abastecimento de água e esgoto, além de problemas relacionados à saúde pública, causando elevados custos para o poder público em serviços de manutenção, substituição e remoção.

\section{POLÍTICA PÚBLICA DE MOBILIDADE URBANA}

Atualmente, dentre os principais problemas advindos do processo de urbanização que, neste caso, está em estágio avançado, está a falta de planejamento urbano adequado. A principal preocupação está na falta de infraestrutura urbana para recepcionar o crescimento demográfico aliado ao êxodo rural que vai da carência de saneamento básico à falta de mobilidade dentro das cidades.

Fica evidente a necessidade e a urgência de harmonizar os movimentos de bens e de pessoas com agilidade, eficiência, conforto e segurança, além de mitigar os impactos negativos gerados pelo transporte urbano, especialmente os congestionamentos, os acidentes, a poluição visual, atmosférica e sonora, bem como a exclusão social. Nesse sentido, o Ministério das Cidades e o Instituto Pólis (2005) relatam que pensar a mobilidade urbana é, portanto, pensar sobre como organizar os usos e a ocupação da cidade e a melhor forma de garantir o acesso das pessoas e bens ao que a cidade oferece, e não apenas pensar os meios de transporte e trânsito.

Nesse contexto, para o Ministério das Cidades, a mobilidade urbana sustentável deve ser pensada como o resultado de um conjunto de políticas de transporte e circulação que visam proporcionar o acesso amplo e democrático ao espaço urbano, de maneira efetiva, socialmente inclusiva e ecologicamente sustentável. (BRASIL, 2006).

Para a European Conference of Ministers of Transport (ECMT, 2006), independente dos meios de transportes, se o passeio público estiver tomado por obstáculos, a usabilidade daquele serviço 
estará comprometida. Nesse sentido, nota-se a importância do deslocamento a pé nos planos de mobilidade urbana.

A Lei n. 12.587, de 3 de janeiro de 2012 traz dentre seus princípios o desenvolvimento sustentável das cidades, nas dimensões socioeconômicas e ambientais, segurança nos deslocamentos das pessoas, equidade no uso do espaço público de circulação, vias e logradouros e eficiência, eficácia e efetividade na circulação urbana. (BRASIL, 2012). E dentre seus objetivos encontra-se proporcionar melhoria nas condições urbanas da população no que se refere à acessibilidade e à mobilidade.

Esta abordagem tem como centro das atenções o deslocamento das pessoas e não dos veículos, considerando, especialmente, aquelas que possuem restrição de mobilidade. É nesse contexto, que se inserem os novos conceitos aliados a mobilidade urbana, dentre eles: o acesso amplo e democrático à cidade, a universalização do acesso ao transporte público, a acessibilidade universal de pessoas no desenho urbano e a valorização dos deslocamentos de pedestres e ciclistas, em detrimento dos demais modais motorizados. (BRASIL, 2007).

Na sua essência, a acessibilidade é entendida como equiparação das oportunidades de acesso ao estudo, trabalho, lazer, bem-estar social e econômico, enfim, à concretização de objetivos que são direitos universais.

As necessidades de deslocamentos são intrínsecas ao cotidiano da população, portanto, deve-se preocupar em garantir essa mobilidade de forma segura, eficiente, com desenho universal e sustentável para todos. Segundo Aguiar (2010), o conceito de desenho universal é uma filosofia de projeto que contempla a necessidade de todos os usuários.

Sendo assim, a mobilidade urbana deve atender aos princípios da sustentabilidade não só no que diz respeito à implantação de sistemas intermodal de transportes, mas também por calçadas confortáveis, niveladas, sem buracos e livres de obstáculos, atendendo assim, de forma igualitária a todos os usuários (cadeirantes, idosos, crianças, gestantes, pessoas com deficiência temporária ou permanentes).

Observa-se que tais legislações não são concorrentes, pelo contrário, elas se completam, mas devido a seu caráter geral devem 
ser adaptadas a nível municipal devido as suas especificidades. No entanto, o descaso com a lei de mobilidade urbana é percebido quando mais de $70 \%$ das 27 capitais brasileiras e demais cidades com mais de 500 mil habitantes e $95 \%$ do total de municípios acima de 50 mil habitantes não têm plano de mobilidade pronto, cujo prazo final para elaboração pelas cidades com mais de 20 mil habitantes era abril de 2015. (MARCHIORI, 2015).

Nesse contexto, o objetivo deste estudo é mostrar que, na prática, nem sempre essas Políticas estão em acordo uma com as outras, ou seja, observa-se a total falta de sinergia entre a Política Pública de Meio Ambiente e a de Mobilidade Urbana na cidade de Resende (RJ).

\section{MATERIAL E MÉTODO}

\section{1 Área de estudo}

O estudo foi realizado na cidade de Resende, município localizado no Sul do estado do Rio de Janeiro, na região do Vale Médio Paraíba, a 395m de altitude, com população de 119.769 habitantes, sendo aproximadamente $94 \%$ urbana. Possui clima tropical de altitude com temperatura média de $25^{\circ} \mathrm{C}$, com média pluviométrica anual de $1.500 \mathrm{~mm}^{3}$. As maiores precipitações são no período entre novembro e março. Possui grande extensão territorial, $1.095,254 \mathrm{~km}^{2}$, a maior do eixo Rio - São Paulo, dentre os municípios percorridos pela rodovia Presidente Dutra, que liga as duas metrópoles. (INSTITUTO BRASILEIRO DE GEOGRAFIA E ESTATÍSTICA, 2011).

A pesquisa foi desenvolvida em um trecho cujo ponto médio está localizado a $22^{\circ} 27^{\prime} 54.73^{\prime \prime} \mathrm{S}$ e $44^{\circ} 27^{\prime} 25.17^{\prime}$ 'O, de aproximadamente $1.060 \mathrm{~m}$, conforme demarcado na Foto 1, por ser um percurso de grande movimentação de transeuntes e, que se assemelha com áreas estudadas por Santos e Freitas (2014). 


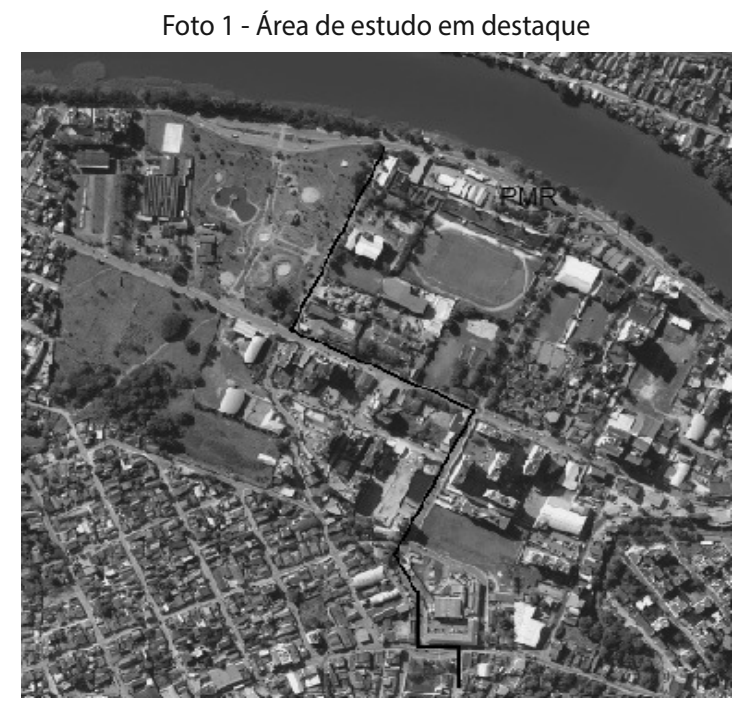

Fonte: RESENDE. Prefeitura Municipal. Câmara Municipal. Sistema de Informação Geográficas para Gestão Territorial. 2009.

\subsection{Resultado e discussão}

Não obstante os efeitos positivos gerados pela arborização nas cidades, conforme Roppa e outros (2007) como redução da poluição do ar, minimização da poluição sonora, amenização da força do vento, favorecimento de um micro clima, contribuição para o balanço hídrico, além de fornecer abrigo e alimentação para a fauna local e agregar valor estético à paisagem, dentre outros, a arborização urbana, nos passeios públicos, e outros elementos existentes na maioria dos centros urbanos como postes de iluminação pública, fiações, telefones públicos, placas de sinalização, pontos de ônibus, lixeiras, materiais de construção, carros estacionados nas calçadas, exposição de mercadorias, dentre outros, convivem em desarmonia com o meio devido à falta de planejamento tanto para arborização, quanto desses outros componentes que ocupam o mesmo espaço.

Segundo a Carta Magna, é concomitante aos entes federados esse planejamento. Sendo assim, cita-se como bom exemplo a cidade de Campinas (SP), que disciplina o plantio, o replantio, a poda, a supressão e o uso adequado e planejado da arborização urbana, através da Lei $\mathrm{n}^{\circ} 11.571$, de 17 de junho de 2003, onde o munícipe 
não é obrigado a plantar na calçada e, caso queira, deve ter autorização do Órgão Ambiental, observada nas recomendações do Guia de Arborização Urbana da Cidade.

Outro modelo adequado de gestão pública vem da cidade de São Paulo, que possui um Manual Técnico de Arborização Urbana, onde são determinados parâmetros para arborização de passeios em vias públicas, como por exemplo, plantio somente em calçadas com largura superior a $1,50 \mathrm{~m}$, deixando no mínimo espaço de $1,20 \mathrm{~m}$ para o trânsito de pedestres. (SÃO PAULO, 2005).

$\mathrm{O}$ art. $10^{\circ}$, da Lei Orgânica do Município de Resende, destaca dentre as competências do município a promoção de forma adequada do ordenamento territorial mediante planejamento e controle do uso, parcelamento e ocupação do solo urbano e, a execução da política de desenvolvimento urbano com objetivo de ordenar as funções sociais, garantindo assim o bem-estar dos habitantes. $\mathrm{O}$ art. $116^{\circ}$ traz a obrigação de conservar os recursos naturais e paisagísticos e no art. $236^{\circ}$ a garantia aos portadores de deficiência física das condições para seu desenvolvimento social. (RESENDE, 1997).

Considerando legislações mais específicas sobre o assunto tem-se a Lei Municipal $\mathrm{n}^{\circ} 2.819$, de 13 de abril de 2011, que consolida as normas de construção, manutenção e recuperação do passeio público e calçadas cujo objetivo é assegurar a acessibilidade e segurança aos pedestres, em especial às pessoas com deficiência. (RESENDE, 2011). No seu art. $9^{\circ}$, transcreve que a instalação de mobiliário urbano nos passeios públicos não deverá bloquear, obstruir ou dificultar o livre trânsito dos pedestres, em especial as pessoas portadoras de deficiência.

Já a Lei Municipal $\mathrm{n}^{\circ} 2.245$, de 23 de novembro de 2000, no seu art. $6^{\circ}$, vincula a concessão do Habite-se para o imóvel ao plantio, pelo proprietário, de uma muda de árvore no passeio fronteiriço, de acordo com as espécies vegetais e números de exemplares que forem indicados pelo órgão municipal responsável pelo meio ambiente; nesse caso, a Agência Municipal de Meio Ambiente (AMAR).

Entretanto, segundo a NBR 9050/2004, de acessibilidade a edificações, mobiliário, espaços e equipamentos urbanos no seu item de circulação externa quanto das interferências nas faixas livres, cita que as calçadas devem ser completamente desobstruídas e isentas de interferências tais como vegetação, mobiliário e equipamentos de 
infraestrutura urbana, orlas de árvores e jardineiras, rebaixamentos para acesso de veículos, bem como qualquer outro tipo de interferência ou obstáculo que reduza a largura da faixa livre. Ainda segundo a NBR 9050/2004, os pisos devem ter superfície regular, firme, estável e que não provoquem trepidação em dispositivos de rodas, como por exemplo, os carrinhos de bebê. (ASSOCIAÇÃO BRASILEIRA DE NORMAS TÉCNICAS, 2004).

A não observância dos preceitos da NBR 9050/2004 acarreta sérios prejuízos não só a área ambiental, mas também à mobilidade urbana. Vale ressaltar o conflito político na tomada de decisão, pois, a Secretaria responsável pela liberação do Habite-se é a de Obras, que libera o mesmo após verificação (por meio de seus fiscais) da existência do plantio, não se importando em qual espaço da calçada a muda foi plantada, e qual a espécie plantada, competências do Orgão Ambiental, que por sua vez raramente interfere nesse processo. O resultado é o apresentado em sequência.

Habite-se do imóvel liberado, mesmo tendo a mobilidade urbana prejudicada pelo plantio de uma muda de Grevillea banksii alba (grevilea), árvore de origem Australiana, plantada no meio do passeio público, que possui piso com certo grau de declividade e forma irregular de acabamento, inviabilizando uso por cadeirantes e idosos, conforme evidenciado na Foto 2.

Foto 2 - Espécie exótica e plantio inadequado

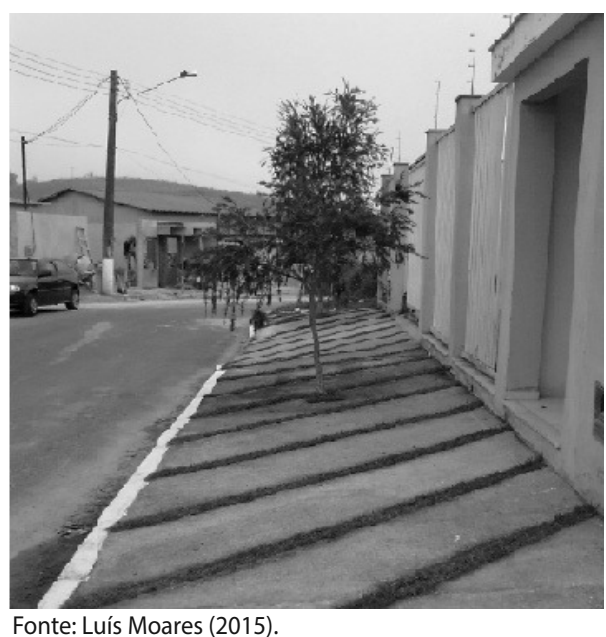


Em pesquisa realizada por Santos e Freitas (2014, p. 18-19), onde foram ouvidos especialistas na área de mobilidade, o resultado mais expressivo (97\%) se apresentou na categoria de calçadas: promover acessibilidade para pessoas com necessidades especiais - acessibilidade universal e apresentar calçadas largas, livres de obstáculos e completas, incluindo faixa de mobiliário, de circulação e de acesso ao terreno. As demais medidas apresentaram pelo menos $80 \%$ de aprovação, exceto a medida "[...] apresentar inclinação adequada do corte da calçada, para não empoçar água da chuva.", que obteve $60 \%$ de avaliações positivas.

Sendo assim, o trecho escolhido se fundamenta na pesquisa dos autores por considerar que apresenta situações semelhantes à pesquisa desenvolvida aos encontrados no passeio público de Resende/RJ. A Foto 3 mostra o plantio de árvore embaixo da fiação de iluminação, quase no centro do passeio público. Observa-se que já foi realizada uma poda em V, considerada drástica, segundo Rossetti, Pellegrino e Tavares (2010), porém, sem sucesso.

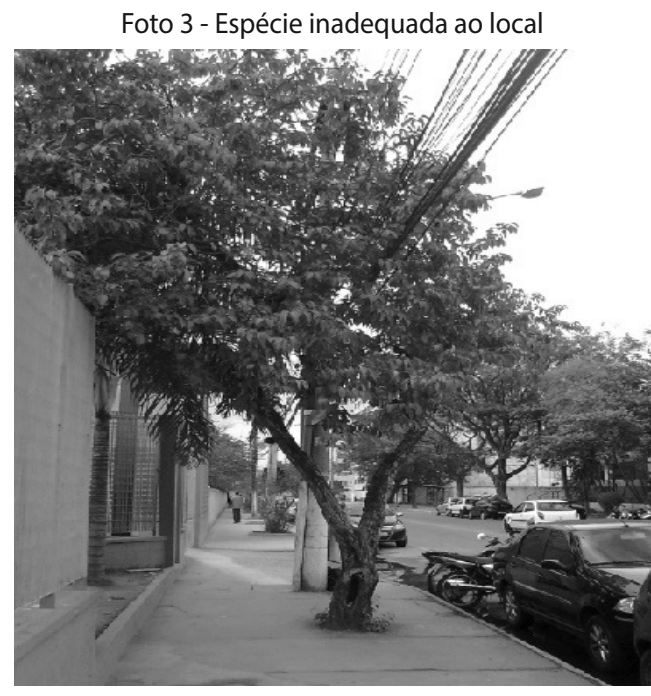

Fonte: Luís Moares (2015)

Na mesma calçada, que possui em determinados trechos piso irregular, nota-se postes de iluminação, hidrante (Foto 4), além de árvores plantadas em canteiros de $1.50 \mathrm{~m}$ x 1,50m (Foto 5), restringindo e dificultando o tráfego de pedestres no local. 
Foto 4 - Piso irregular /obstáculos na calçada

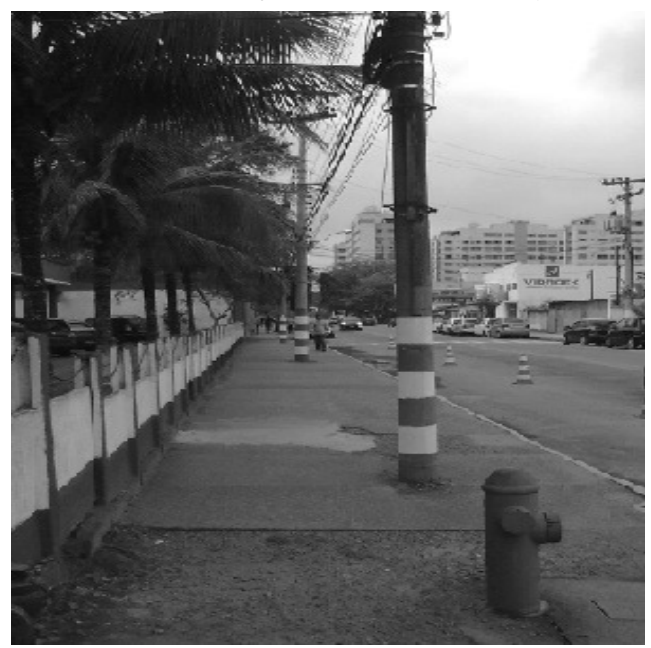

Fonte: Luís Moares (2015).

Foto 5 - Tamanho inadequado de canteiro

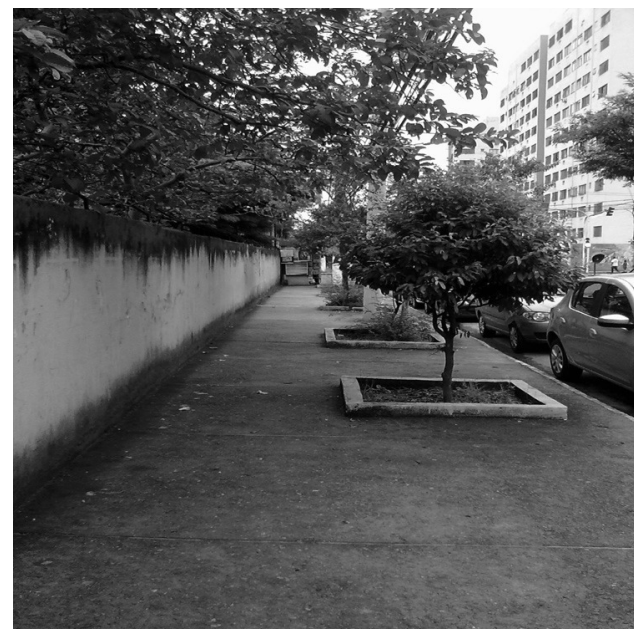

Fonte: Luís Moares (2015).

Na Foto 6, observa-se poste de iluminação, colocado recentemente (março de 2016), em uma calçada de $1 \mathrm{~m}$ de largura com sobra de $0,78 \mathrm{~m}$ de passagem livre para os pedestres. Medidas que vão de 
encontro a NBR 9050/2004, que determina faixa livre de no mínimo $1,20 \mathrm{~m}$ de largura exclusivamente para fluxo de pedestres, assim como uma faixa de serviço - que serve para acomodar o mobiliário, os canteiros, as árvores e os postes de iluminação ou sinalização, de no mínimo $0,70 \mathrm{~m}$ de largura.

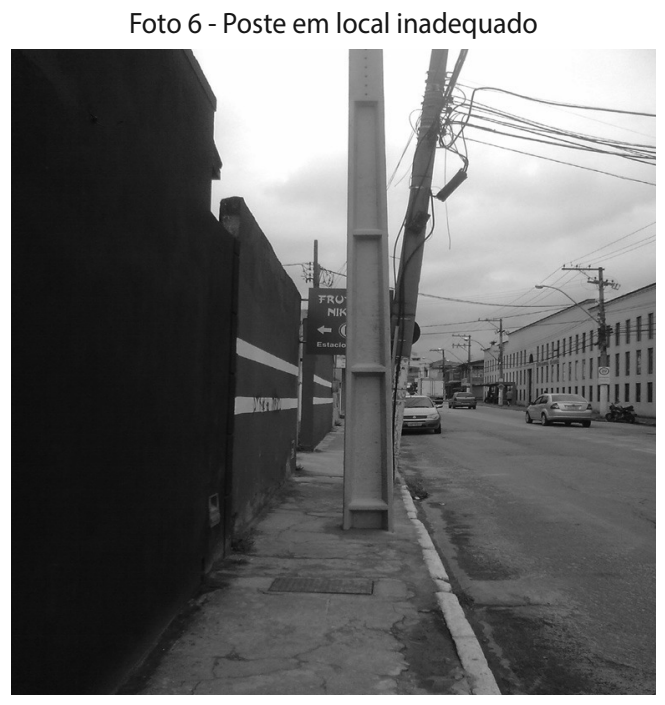

Fonte: Luís Moares (2015).

Ressalta-se que na construção de calçadas, o proprietário do terreno ou imóvel é obrigado a obedecer algumas normas, o que geralmente não acontece, indo de encontro à legislação, municipal e Federal de acessibilidade. A Lei diz, por exemplo, que a pessoa com mobilidade reduzida tem o direito de ir e vir, então, quando se faz uma calçada com degrau, declividade ou mesmo com piso irregular, ou que esteja obstruída pela existência de qualquer item que dificulte ou impossibilite o transeunte de se deslocar, ele não está em consonância com a Lei. O passeio é público para que todos possam passar por ele, no entanto, sua manutenção é privada, portanto, o proprietário é obrigado a fazer sua calçada e mantê-la em condições de acessibilidade, entretanto, para Wilheim (2013) essa norma tem se comprovado deficiente.

A Foto 7 evidencia a calçada danificada pelo plantio inadequado da espécie Ficus benjamina L. (figueira), o que dificulta a mobilidade, principalmente de idosos e cadeirantes. 
Foto 7 - Plantio de espécie inadequada de árvore

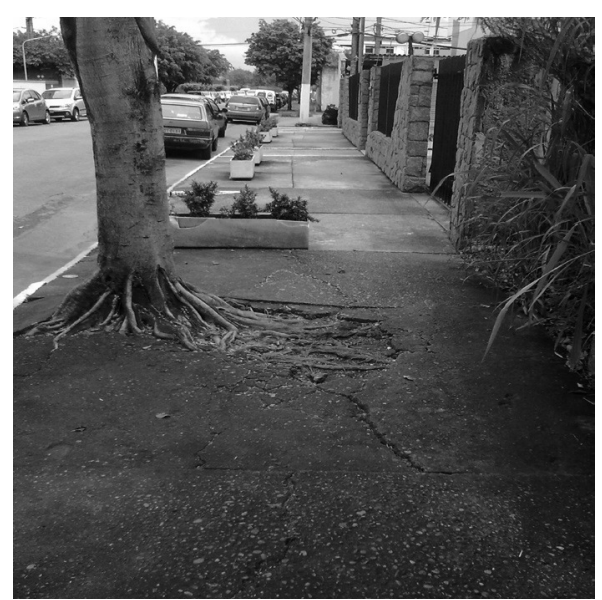

Fonte: Luís Moares (2015).

$\mathrm{Na}$ Foto 8 tem-se uma Bauhinia forficata Link (pata-de-vaca) cuja copa, pela falta de manejo, prejudica a circulação no passeio público, que segundo a NBR 9050/2004 determina que a faixa livre, destinada à circulação de pedestres, deve ser livre de qualquer obstáculo, ter no mínimo 1,20 m de largura e 2,10 m de altura livre.

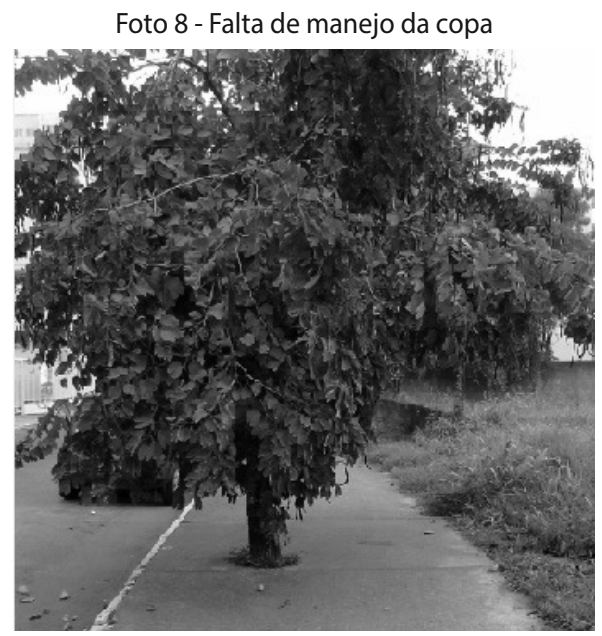

Fonte: Luís Moares (2015). 
As espécies devem ter porte adequado ao espaço disponível do passeio público, bem como ter forma e tamanho de copa compatível com esse espaço. Recomenda-se que para o plantio de árvores em vias públicas, os passeios deverão ter a largura mínima de $2,40 \mathrm{~m}$ em locais onde não é obrigatório o recuo das edificações em relação ao alinhamento, e de $1,50 \mathrm{~m}$ nos locais onde esse recuo for obrigatório.

Na Foto 9, tem-se uma Bauhinia forficata e um Ficus benjamina cuja copa está entre os fios de alta tensão. Verifica-se que foi realizada poda de levantamento de copa em ambas as árvores. Quando for necessária a poda por segurança, devido seu contato com a rede elétrica, pouco vai sobrar das espécies. Normalmente o que se observa na prática, quando isso ocorre, é o disposto na Foto 10, com a morte da espécie arbórea.

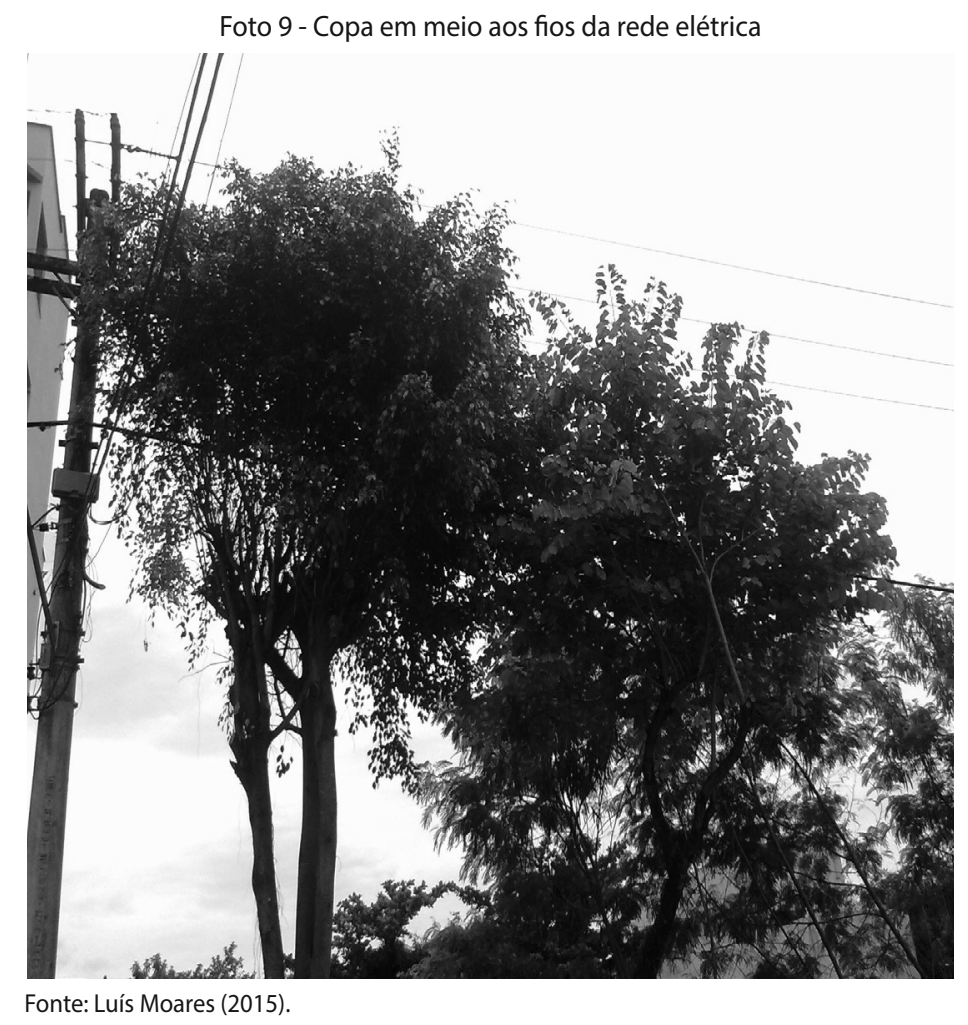




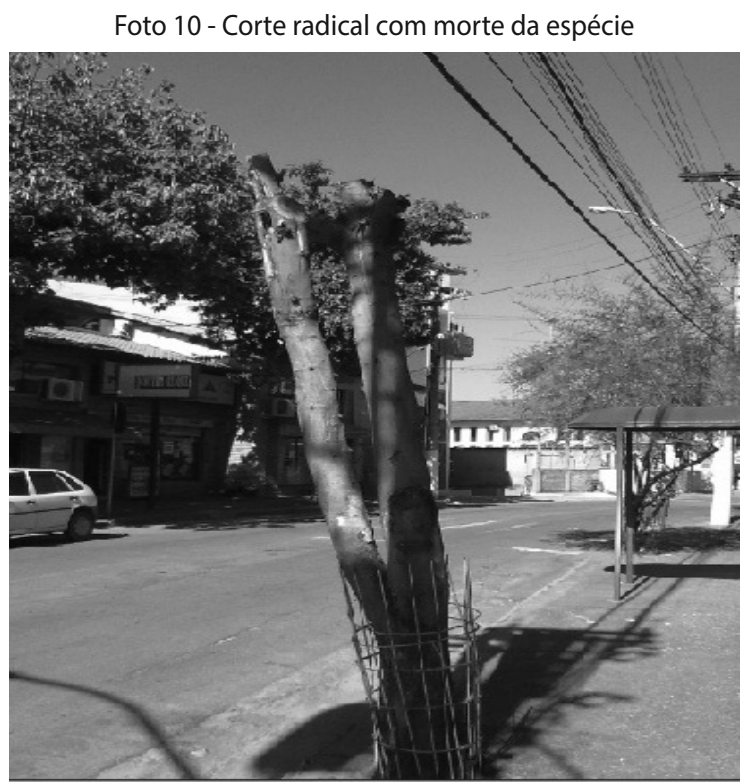

Fonte: Luís Moares (2015).

Com relação às podas, principalmente as radicais, o Ministério Público do Estado do Rio Grande do Sul (MPE/RS), em uma doutrina sobre a matéria, cita a poda como um trágico costume nas cidades brasileiras, principalmente no inverno. "As árvores urbanas são criminosamente decepadas, a pretexto de 'poda'. Isso, à luz de toda a legislação vigente - sem exceção, além de constituir infração e improbidade administrativa (seja por conduta comissiva ou omissiva de administradores públicos), é crime, com tipificação expressa no artigo 49 da Lei 9.605/98." (SANTOS, 2002, p. 184, grifo do autor).

Ainda segundo a doutrina, o MPE/RS relata que a prática da poda foi trazida ao Brasil pelos imigrantes europeus, exclusivamente para árvores frutíferas, visando a maior e melhor produção de frutos e, com o passar do tempo, começou a ser aplicada às demais espécies.

A poda de árvores na zona urbana é uma prática generalizada na mente das pessoas que muitas vezes cometem grandes erros sob a ilusão de estarem realizando a prática mais acertada, conclui. Para Coimbra (2002), é inacreditável que a poda das árvores esteja arrai- 
gada nos Órgãos Ambientais, que as justificam no fortalecimento, rejuvenescimento ou segurança das árvores. Segundo o autor, essa é uma visão equivocada, a poda não rejuvenesce, não fortalece e não a torna menos perigosa. Nesse sentido, para Appio (2005), as políticas públicas consistem em instrumentos estatais que demandam uma combinação de vontade política e conhecimento técnico.

$\mathrm{Na}$ tentativa de se conciliar o ambiental com a mobilidade urbana, a Foto 11 mostra situação próxima à ideal: árvore, de grande porte, plantada em canteiro, com tamanho apropriado, com área permeável permitindo a infiltração da água e aeração do solo, em uma calçada com largura de $3 \mathrm{~m}$, com copa conduzida por meio de trato cultural adequado, sem fio de iluminação, com recuo superior a $1,50 \mathrm{~m}$ da edificação e altura de copa com mais de $2,10 \mathrm{~m}$, conforme NBR 9050/2004.

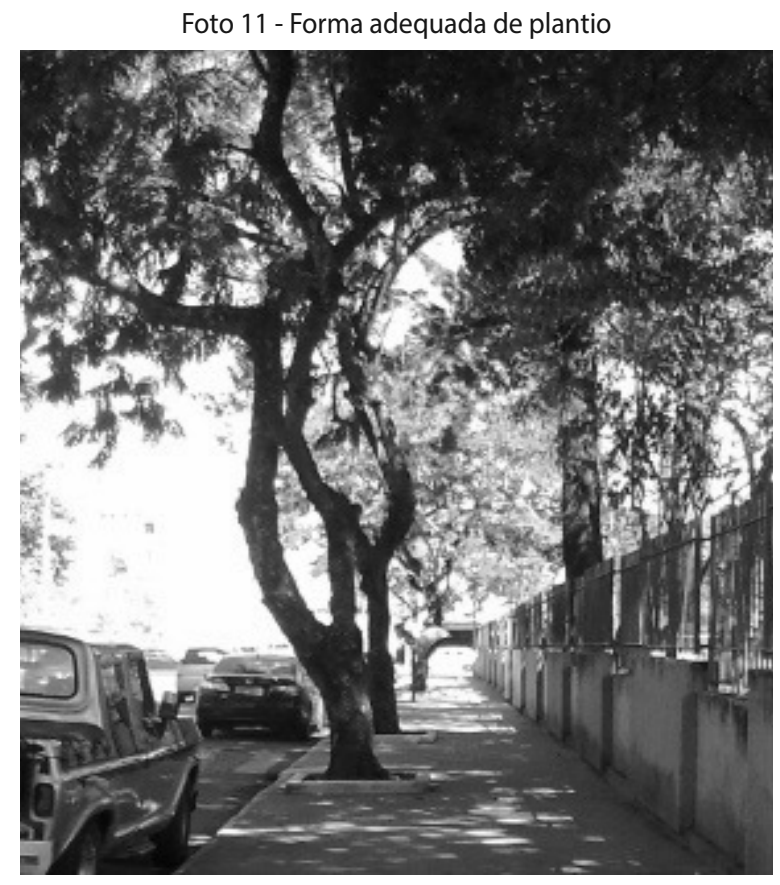

Fonte: Luís Moares (2015). 


\section{CONCLUSÃO}

Diante dos resultados obtidos, verifica-se que a mobilidade fica um tanto quanto prejudicada, principalmente no quesito segurança dos idosos, pessoas portadoras de deficiência física e até por um simples passear com carrinhos de bebês no passeio público, visto a não padronização das calçadas que se encontram com piso irregular, em declive, estreitas, com vários acabamentos e com todos os tipos de obstáculos pelas calçadas.

Em relação à arborização urbana, nota-se que a qualidade do ambiente se apresenta afetada nos aspectos sociais, ambientais e paisagísticos, além do legal, uma vez que se constatou que não há um estudo fitossanitário anterior à poda; após esta não se usa cicatrizante e nem mesmo há um técnico de arboricultura credenciado para realizar tal serviço, ou seja, a poda é feita sem nenhum critério técnico. Somam-se a isso as considerações da Lei de Crime Ambientais no que se refere ao art. 49.

Sendo assim, com o aumento da urbanização torna-se cada vez mais necessária a realização de estudos que contribuam com o planejamento urbano, de maneira a melhorar não só a qualidade funcional e logística das cidades, mas, também, a qualidade de vida dos seus cidadãos, sendo a vegetação um dos principais fatores nesse processo.

A gestão pública das políticas deve ser compreendida, planejada e implementada de forma articulada umas com as outras, por meio de uma legislação mais adequada, includente, efetiva e eficiente que busque ações que atuem entre o meio natural e o construído, obtendo, assim, uma maior qualidade de vida para a população.

Pensar de maneira a conciliar a arborização urbana, criando critérios e normas, para que ela possa cumprir com seus benefícios, com acessibilidade e mobilidade dos transeuntes de maneira segura e confortável é um desafio ainda a ser superado.

\section{REFERÊNCIAS}

AGUIAR, F. de O. Acessibilidade relativa dos espaços urbanos para pedestres com restrições de mobilidade. 2010. 170 f. Tese (Doutorado) - Escola de Engenharia de São Carlos, Universidade de São Paulo, São Paulo, 2010. Disponível em:<www.teses.usp.br/teses/ 
disponiveis/18/18144/tde-21042010-193924/...tese.pdf\$. Acesso em: 29 fev. 2016.

ÁPPIO, E. Controle judicial das políticas públicas no Brasil. Curitiba: Juruá, 2005.

ASSOCIAÇÃO BRASILEIRA DE NORMAS TÉCNICAS. NBR 9050: acessibilidade a edificações, mobiliário, espaços e equipamentos urbanos. Rio de Janeiro, 2004.

BASSO, J. M.; CORRÊA, R. S. Arborização urbana e qualificação da paisagem. Paisagem e Ambiente: Ensaios, São Paulo, n. 34, p. 129148, 2014.

BRASIL. Ministério das Cidades. Programa Brasileiro de Acessibilidade Urbana. Construindo uma Cidade Acessível. Brasília, DF, 2007. Caderno 2.

; INSTITUTO PÓLIS. Mobilidade urbana é

desenvolvimento urbano! Brasília, DF, 2005. Disponível em:<http:// www.polis.org.br/publicacoes_interno.asp?codigo $=194>$. Acesso em: 10 ago. 2013.

. Presidência da República. Lei n 6.938 de 31 de agosto de 1981. Dispõe sobre a Política Nacional do Meio Ambiente, seus fins e mecanismos de formulação e aplicação, e dá outras providências. Diário Oficial da União, Brasília, DF, 1981.

. Lei ${ }^{\circ} 10.257$, de 10 de julho de 2001. Regulamenta os arts. 182 e 183 da Constituição Federal, estabelece diretrizes gerais da política urbana e dá outras providências. Diário Oficial da União, Brasília, DF, 2001.

. Lei $\mathbf{n}^{\mathbf{0}} \mathbf{1 2 . 5 8 7}$, de 3 de janeiro de 2012. Institui as diretrizes da Política Nacional de Mobilidade Urbana. Diário Oficial da União, Brasília, DF, 2012.

CARVALHO, M. V. G. S. Um modelo para dimensionamento de calçadas considerando o nível de satisfação do pedestre. 2006. $155 \mathrm{f}$. Tese (Doutorado) - Escola de Engenharia de São Carlos, Universidade de São Paulo, São Paulo, 2006.

COIMBRA, F. Se as árvores falassem. Jornal da Mealhada, Lisboa, mar. 2002.

EUROPEAN CONFERENCE OF MINISTERS OF TRANSPORT. Improving Transport Accessibility for all: guide to good practice. Paris, 2006 Disponível em: http://www.internationaltransportforum. org/IntOrg/ecmt/pubpdf/06TPHguide.pdf. Acesso em 29 fev. 2016. 
INSTITUTO BRASILEIRO DE GEOGRAFIA E ESTATÍSTICA.

Censo Demográfico 2010. Rio de Janeiro, 2011. Disponível em: $<$ http://www.ibge.gov.br/estadosat/perfil.php?sigla=am $>$. Acesso em: 12 mar. 2013.

KEPPE JR., C. L. G. Formulação de um indicador de acessibilidade das calçadas e travessias. 2007. 120 f. Dissertação (Mestrado). Universidade Federal de São Carlos, São Carlos, 2007.

LUNARO, A. Avaliação dos espaços urbanos segundo a percepção das pessoas idosas. 2006. 107 f. Dissertação (Mestrado) - Programa de Pós-Graduação em Engenharia Urbana, Universidade Federal de São Carlos, São Carlos, 2006.

MAGAGNIN, R. C.; SILVA, A. N. R. da. A percepção do especialista sobre o tema mobilidade urbana. Transportes, São Paulo, v. XVI, n. 1, p. 25-35, jun. 2008.

MARCHIORI, R. Maiores cidades do Paraná não têm plano de mobilidade concluído. Gazeta do Povo, Curitiba, 2015. Disponível em:<http://www.gazetadopovo.com.br/vida-e-cidadania/maiorescidades-do-parana-nao-tem-plano-de-mobilidade-concluido4vatske8wbgs8nsyitjhqpfj2>. Acesso em: 11 ago. 2015.

MARTINI, A. et al. Microclima em diferentes tipologias de floresta urbana. Revista da Sociedade Brasileira de Arborização Urbana, Piracicaba, SP, v. 10, n. 4, p. 12-22, 2015.

PROVENZI, G. Áreas verdes urbanas em Xaxim, um processo de revisão. 2008. 110 p. Monografia (Especialização em Arquitetura de Interiores) - Universidade do Oeste de Santa Catarina, Xanxerê, 2008.

RESENDE. Prefeitura Municipal. Câmara Municipal. Lei Orgânica do Município de Resende. 1997. Disponível em: http://resende.rj.gov.br/ conteudo/downloads/site_lei_organica.pdf. Acesso em: 25 maio 2017.

Lei no 2819 de 13 de abril de 2011. Consolida

as normas de construção, manutenção e recuperação do passeio público e calçadas do Município de Resende e ambiente, e dá outras providências. Boletim Oficial do Poder Executivo do Município de Resende, Resende, ano 3, n. 015, abr. 2011. Territorial. 2009 . Sistema de Informação Geográficas para Gestão

ROPPA, C. et al. Diagnóstico da percepção dos moradores sobre a arborização urbana na Vila Estação Colônia - bairro Camobi, Santa 
Maria - RS. Revista da Sociedade Brasileira de Arborização Urbana, Piracicaba, SP, v. 2, n. 2, p. 11-30, 2007.

ROSSETTI, A. I. N; PELLEGRINO, P. R. M.; TAVARES, A. R. As Árvores e suas Interfaces no Ambiente Urbano. Revista da Sociedade Brasileira de Arborização Urbana, Piracicaba, SP, v. 5, n. 1, p. 1-24, 2010.

SANTOS, D. V. C.; FREITAS, I. M. D. P. Medidas de Mobilidade Urbana Sustentável (MMUS): propostas para o licenciamento de pólos geradores de viagens. Transportes, v. 22, n. 2, 2014. Disponível em: $<$ https://www.revistatransportes.orgs.br/anpet/article/ view/689/512>. Acesso em: 25 maio 2017.

N. K. dos. Poda da arborização urbana: ultraje ao ambiente e à sustentabilidade da cidade. Revista de Direito Ambiental, São Paulo, v. 7, n. 26, p. 182-194, abr./jun. 2002. Texto divulgado no site do Ministério Público do Estado do Rio Grande do Sul.

SÃO PAULO. Prefeitura da Cidade de São Paulo. Secretaria do Verde e do Meio Ambiente. Manual Técnico de Arborização Urbana. 2. ed. São Paulo, 2005. Disponível em:<http://www.prefeitura.sp.gov.br/ cidade/secretarias/upload/manual_arborizacao_1253202256.pdf $>$. Acesso em: 18 jul. 2013.

WILHEIM, J. Mobilidade urbana: um desafio paulistano. Estudos avançados, São Paulo, v. 27, n. 79, 2013. Disponível em:<http://www. revistas.usp.br/eav/article/view/68699/71279>. Acesso em: 29 fev. 2016.

YUASSA, V. N. Impacto da Hierarquia Viária Orientada para o automóvel no Nível de Serviço de Motos Não Motorizados. 2008. 188 f. Dissertação (Mestrado) - Escola de Engenharia de São Carlos, Universidade de São Paulo, São Paulo, 2008.

\section{NOTA}

1 Reportagem intitulada Calçadas perto dos estádios construídos para a copa já precisam de manutenção, exibida no Programa Bom Dia Brasil (Disponível em: http://globotv. globo.com/rede-globo/bom-dia-brasil/t/edicoes/v/calcadas-perto-dos-estadiosconstruidos-para-a-copa-ja-precisam-de-manutencao/4384141/. Acesso em: 12 ago. 2015). 
